\title{
Fatal Disseminated Tuberculosis and Concurrent Disseminated Cryptococcosis in a Ruxolitinib-treated Patient with Primary Myelofibrosis: A Case Report and Literature Review
}

\author{
Asuka Ogai ${ }^{1}$, Kazuma Yagi $^{2}$, Fumimaro Ito $^{2}$, Hideharu Domoto ${ }^{3}$, Tetsuya Shiomi ${ }^{2}$ and \\ Kenko Chin ${ }^{1}$
}

\begin{abstract}
:
Ruxolitinib, a Janus kinase inhibitor, improves symptoms in patients with myelofibrosis. However, its association with the development of opportunistic infections has been a concern. We herein report a 71-year-old man with primary myelofibrosis who developed disseminated tuberculosis and concurrent disseminated cryptococcosis during ruxolitinib treatment. We also reviewed the literature on disseminated tuberculosis and/or cryptococcosis associated with ruxolitinib treatment. This is the first case of disseminated tuberculosis and concurrent disseminated cryptococcosis during treatment with ruxolitinib. We therefore suggest considering not only disseminated tuberculosis but also cryptococcosis in the differential diagnosis of patients with abnormal pulmonary shadows during ruxolitinib treatment.
\end{abstract}

Key words: Janus kinase inhibitor, primary myelofibrosis, ruxolitinib, disseminated tuberculosis, disseminated cryptococcosis

(Intern Med Advance Publication)

(DOI: 10.2169/internalmedicine.6436-20)

\section{Introduction}

Primary myelofibrosis (PMF) is a myeloproliferative disorder characterized by bone marrow fibrosis, splenomegaly, and anemia. Ruxolitinib, a selective inhibitor of Janus kinase (JAK1 and JAK2), was approved for myelofibrosis in 2011 by the US Food and Drug Administration. Specifically, ruxolitinib improves disease-related splenomegaly and constitutional symptoms (1-4). However, the inhibition of the JAK-signal transducer and activator of transcription (STAT) pathway may lead to the dysfunction of cellular immunity (5), which results in decreased production of several proinflammatory cytokines $(4,6-10)$. Consequently, various opportunistic infections related to ruxolitinib treatment have been reported previously $(4,11-25)$.

Both disseminated tuberculosis and cryptococcosis sometimes occur in immunocompromised hosts, such as patients with human immunodeficiency virus (HIV) (26). However, there are a limited number of reports on disseminated tuberculosis and concurrent cryptococcosis in patients who are not infected with HIV (27-31).

We herein report the first case of disseminated tuberculosis and concurrent disseminated cryptococcosis during treatment with ruxolitinib. We also provide a review of previously reported cases of disseminated tuberculosis and cryptococcosis associated with ruxolitinib treatment to further understand how ruxolitinib affects tuberculosis and cryptococcosis.

\section{Case Report}

A 71-year-old man with PMF who was treated with ruxolitinib for 2.5 years presented to our hospital with itchy erythema for a week on the right side of his neck and a remittent fever for a month (temperature, $37-39{ }^{\circ} \mathrm{C}$ ). The pa-

${ }^{1}$ Department of Hematology, Department of Medicine, Keiyu Hospital, Japan, ${ }^{2}$ Department of Pulmonary Medicine, Department of Medicine, Keiyu Hospital, Japan and ${ }^{3}$ Department of Pathology, Keiyu Hospital, Japan

Received: October 7, 2020; Accepted: August 16, 2021; Advance Publication by J-STAGE: September 25, 2021

Correspondence to Dr. Kazuma Yagi, kazumayagi1214@gmail.com 


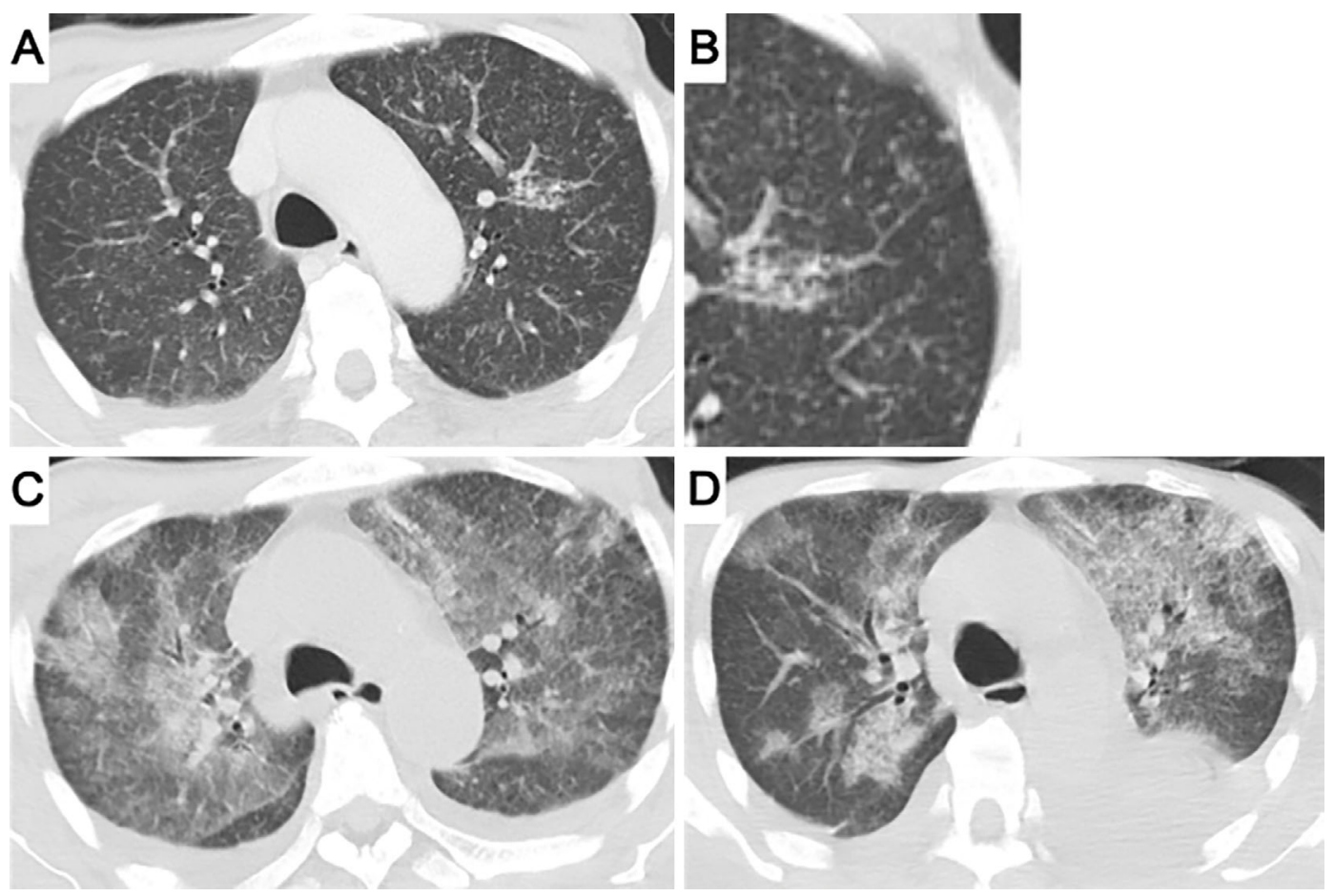

Figure 1. Chest computed tomography (CT) findings. (A) (B) Chest CT performed at the time of the first fever workup (on the eighth hospital day), showing multiple pulmonary micronodules in the bilateral lungs. (C) Chest CT performed around the time of oxygen supplementation (on the 13th hospital day), showing reticular opacities, infiltration, and ground-glass opacities in the bilateral lungs. (D) Chest CT performed on the morning of the patient's death (on the 22nd hospital day), showing reticulation, infiltration, and ground-glass opacities with exacerbation of pleural effusion.

tient had no diagnosis or treatment history of tuberculosis and no close contact with anyone recently diagnosed with tuberculosis. The patient had been diagnosed with myeloproliferative disorder six years and seven months before hospitalization and also been diagnosed with PMF three years and six months before hospitalization, as increased argyrophilic fibers were detected on a bone marrow examination.

The Dynamic International Prognostic Scoring System (DIPSS) for PMF (32) and refined DIPSS for PMF, which incorporates prognostic information from the karyotype, platelet count, and transfusion status (DIPSS plus) (33), at the time of the diagnosis revealed a score of 3 points (intermediate- 2 risk) and 3 points (intermediate- 2 risk), respectively. As the disease status, including the symptoms, had been stable, the patient had been followed up without treatment until two and a half years before hospitalization.

Despite a lack of remarkable symptoms, computed tomography (CT) performed two and a half years before hospitalization had revealed longitudinal splenomegaly, following which ruxolitinib was initiated. Although the disease status was well-controlled by ruxolitinib, thrombocytopenia progressed about a year later. Two months before the admission, blood transfusions had been initiated for worsening anemia and thrombocytopenia with leukocytosis.

On admission, the patient had no respiratory symptoms. His body temperature was $37.3{ }^{\circ} \mathrm{C}$, and his percutaneous oxygen saturation was $97 \%$ on room air. Except for the characteristic shingles rash on his right neck and arm, the findings on a physical examination were unremarkable. Laboratory data revealed anemia (hemoglobin $7.8 \mathrm{~g} / \mathrm{dL}$ ), thrombocytopenia $(13,000$ cells $/ \mu \mathrm{L})$, and leukocytosis $(149,500$ cells $/ \mu \mathrm{L})$ with $28 \%$ polymorphonuclear cells, $3.5 \%$ lymphocytes, and $1.5 \%$ blast cells on the day of hospitalization. The levels of alkaline phosphatase (607 U/L) and lactate dehydrogenase (668 U/L) were elevated, and the level of C-reactive protein was $0.46 \mathrm{mg} / \mathrm{dL}$. HIV antibodies were undetectable. The DIPSS and DIPSS plus at the time of the admission revealed scores of 6 points (high risk) and 8 points (high risk), respectively, which were much higher than those at the time of the diagnosis.

First, intravenous administration of acyclovir was initiated for herpes zoster virus infection. On the fourth hospital day, the shingles rash became crusted, and acyclovir was administered for a total of seven days. On the seventh hospital day, the patient suddenly developed a high fever $\left(39^{\circ} \mathrm{C}\right)$. Although he had no other symptoms, a urine test performed as a workup for the fever showed pyuria. He was clinically diagnosed with urinary tract infection, and intravenous ampicillin/sulbactam (6 g/day) was administered as empiric antibiotic therapy.

Chest CT performed on the eighth hospital day revealed multiple pulmonary micronodules with a random pattern in the bilateral lungs (Fig. 1A and B). We suspected disseminated tuberculosis as a differential diagnosis. Despite abnor- 


ACV ABPCISBT

Ruxolitinib

IU
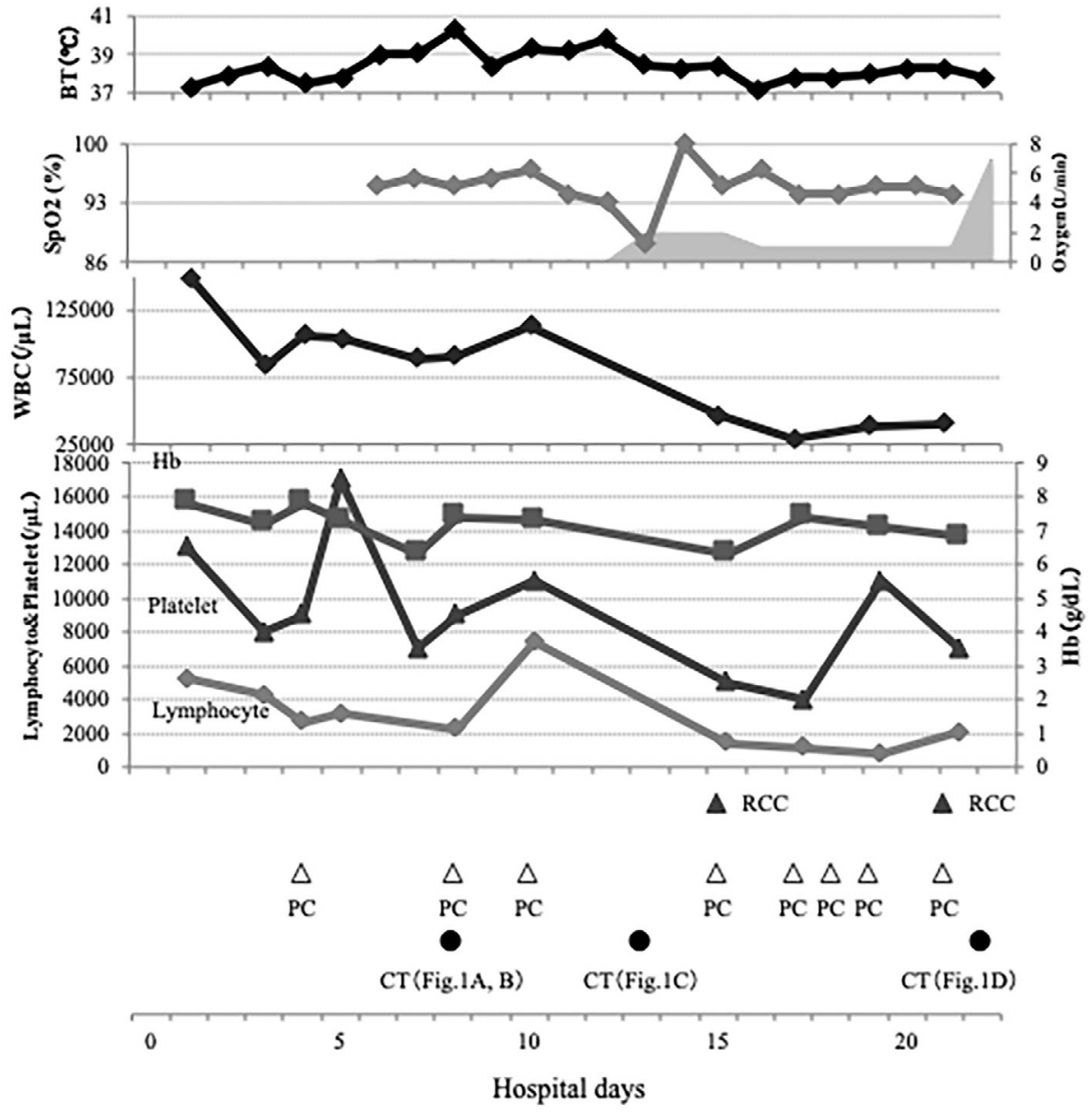

Figure 2. Clinical course of the present case. ABPC/SBT: ampicillin/sulbactam, ACV: acyclovir, BT: body temperature, CT: computed tomography, Hb: hemoglobin, HU: hydroxyurea, PC: platelet concentrates, PIPC/TAZ: piperacillin/tazobactam, PIt: platelet, RCC: red cell concentrates, SpO2: saturation of percutaneous oxygen, WBC: white blood cell

mal shadows on chest CT, he had no respiratory symptoms, and oxygen saturation was maintained on room air. Acid-fast staining of sputum was performed three times, with all results being negative. In addition, acid-fast staining of the urine, stool, and bone marrow specimens yielded negative results. Blood culture for acid-fact bacilli was also performed, and the result was negative at the time.

The enzyme-linked immunospot assay for interferon- $\gamma$ (TSPOT TB) revealed borderline results (equivocal, 5-7 spots). Although conventional blood cultures, sputum culture tests, and additional laboratory tests, such as those for the serum $\beta$-D-glucan level, galactomannan of Aspergillus fumigatus, and Cytomegalovirus antigen, were also performed for differential diagnoses, all findings were unremarkable. The antigen test for Cryptococcus neoformans was not performed initially. The risk of uncontrollable bleeding-due to thrombocytopenia unresponsive to transfusion-made it difficult to perform invasive examinations, such as bronchoscopy or sampling from the gastric lavage fluid.

At the time, ruxolitinib or the progression of PMF was also suspected as a cause of his fever. Therefore, the treatment for PMF was changed from ruxolitinib to hydroxyurea on the 10th hospital day. On the 13th hospital day, his respiratory condition gradually deteriorated, and his percutaneous oxygen saturation became $94 \%$ while receiving $2 \mathrm{~L} / \mathrm{min}$ of oxygen via a nasal cannula. Chest CT performed on the 13 th day revealed reticulation, infiltration, and ground-glass opacity with traction bronchiectasis in the upper lobe of the bilateral lungs (Fig. 1C). Since the patient still needed blood transfusions more frequently due to worsening anemia and thrombocytopenia with leukocytosis, treatment with hydroxyurea was discontinued on the 17 th hospital day.

The respiratory condition of the patient was relatively stable while receiving $1 \mathrm{~L} / \mathrm{min}$ of oxygen via a nasal cannula 


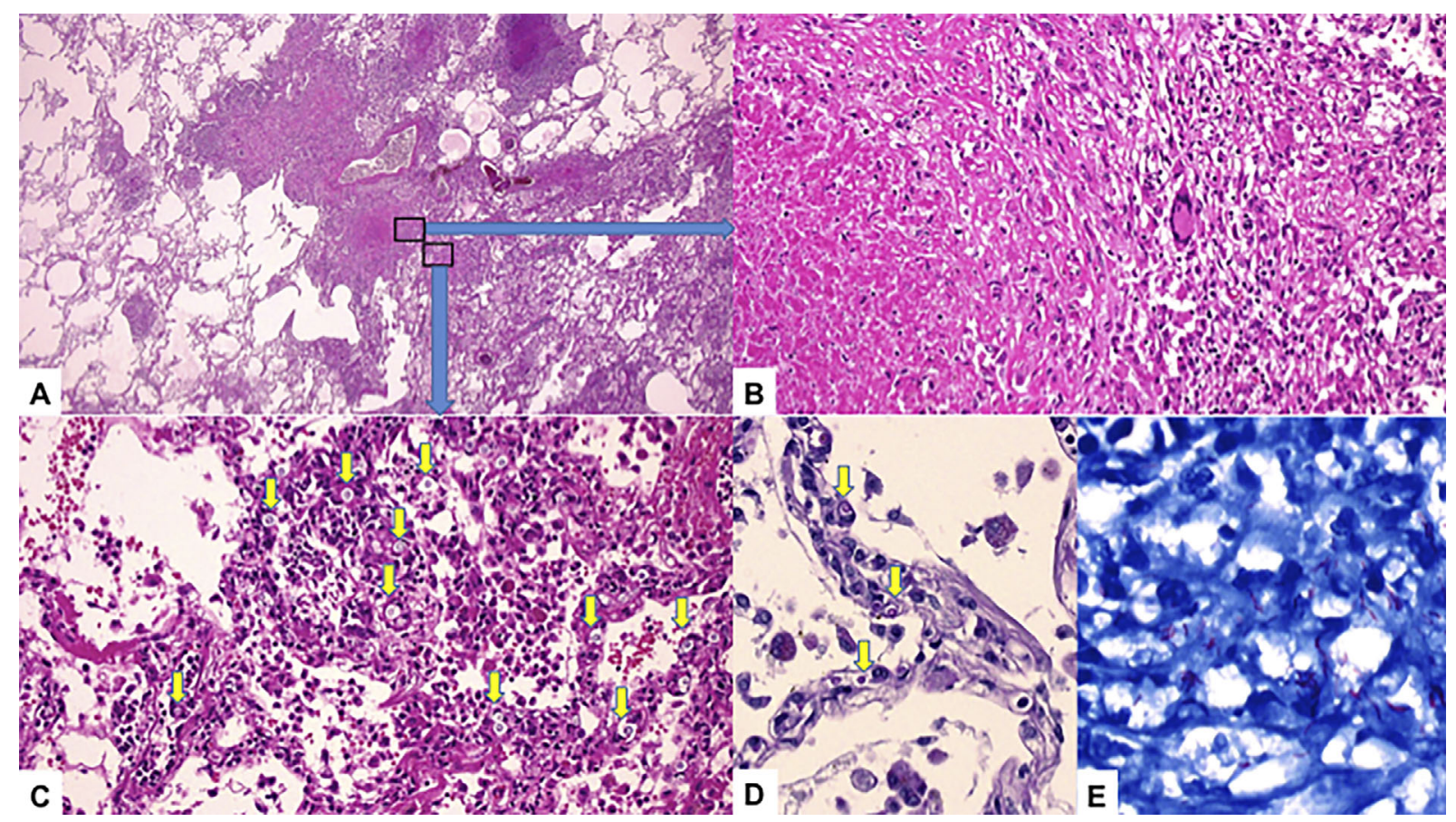

Figure 3. Autopsy findings. (A) Low-power image of the lung shows scattered caseating granulomas indicating miliary tuberculosis [×12.5, Hematoxylin and Eosin $(H \& E)$ staining]. (B) High-power view of the upper-left black rectangle in part A showing caseating necrosis with a Langhans giant cell ( $\times 200, H \& E$ staining). (C) High-power view of the lower-right black rectangle in part A showing inflammatory thickening of alveolar septa with Cryptococcus in the capillaries (yellow arrow) $(\times 200$, H\&E staining). (D) Positive periodic acid-Schiff staining of Cryptococcus capsules (yellow arrow) $(\times 400)$. (E) Ziehl-Neelsen staining of caseating necrosis showing many acid-fast bacilli $(\times 1000)$.

for the next few days. On the 21 st hospital day, the patient began to complain of dyspnea, and his respiratory condition gradually deteriorated. On the 22nd day, his percutaneous oxygen saturation was around $90 \%$ while receiving $6 \mathrm{~L} / \mathrm{min}$ of oxygen via a mask. Chest CT performed on the 22nd day revealed reticulation, infiltration, and ground-glass opacities in the bilateral lungs with exacerbation of pleural effusion (Fig. 1D). His respiratory condition then deteriorated rapidly, and the patient ultimately passed away on the same day due to acute respiratory failure (Fig. 2).

An autopsy revealed many caseating granulomas over the whole lung field (Fig. 3A and B). Histological features of diffuse alveolar damage, such as fibrinous exudate along the alveolar septa and septal edema with infiltration of inflammatory cells, were also observed (Fig. 3C). In addition, Cryptococcus was easily identified with clear spaces around the organisms in the capillaries of the alveolar septa (Fig. 3C and D) and cytoplasm of histiocytes in the alveoli over the whole lung field. The capsules of the fungus were periodic acid-Schiff stain-positive. Furthermore, numerous acid-fast bacilli were identified in the caseating granulomas by Ziehl-Neelsen staining (Fig. 3E). The autopsy findings of the lung showed neither tumor cell infiltration with obvious extramedullary hematopoiesis nor tumor emboli/thrombi. Likewise, mycobacteriosis-related caseating and noncaseating granulomas and proliferating Cryptococcus were observed in the liver, spleen, mediastinal and retroperitoneal lymph nodes (Fig. 4A), bone marrow, and peritoneal surface (Fig. 4B). In addition, numerous Cryptococcus were identified in the heart, spleen, adrenal glands, and thyroid but lacked the associated inflammatory reactions. Consequently, systemic co-infection of tuberculosis and cryptococcosis was confirmed by a histological examination.

On the 14th day after the patient's death, solid media culture and polymerase chain reaction (PCR) of sputum (collected 6 days before death) were found to be positive for $M$. tuberculosis. Furthermore, blood and urine culture for acidfast bacilli collected seven and six days before death also yielded positive results five and four weeks after his death, respectively. The results of PCR of these specimens were also found to be positive for M. tuberculosis. As a result, we concluded that the direct cause of death was acute respiratory failure with diffuse alveolar damage caused by disseminated tuberculosis and concurrent disseminated cryptococcosis.

\section{Discussion}

We presented an autopsy case of fatal disseminated tuberculosis with concurrent disseminated cryptococcosis in a patient with PMF who had been treated with ruxolitinib. To our knowledge, this is the first case of disseminated tuberculosis and concurrent disseminated cryptococcosis following treatment with ruxolitinib. 


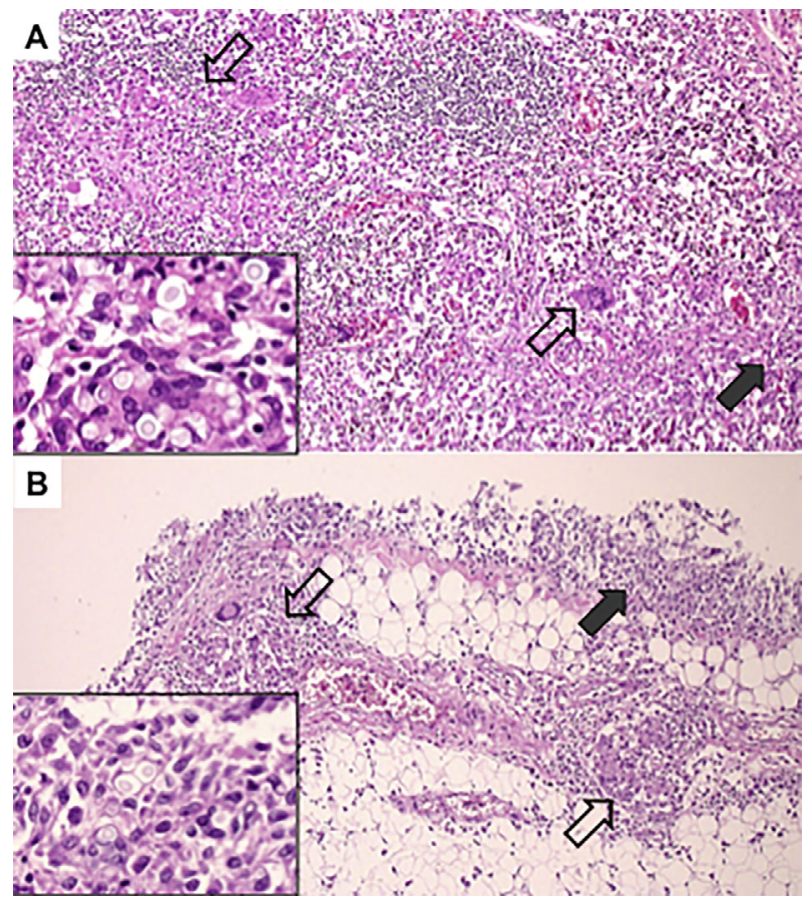

Figure 4. High-power microscopic images of autopsy findings. (A) Lymph node in the hepatoduodenal ligament containing non-caseating granulomas (open black arrows) and proliferation of Cryptococcus (closed black arrow) $[\times 100$, Hematoxylin and Eosin (H\&E) staining]. Inset: High-power view of the open black arrow shows Cryptococcus $(\times 400)$. (B) Peritoneum containing non-caseating granulomas (open black arrows) and proliferation of Cryptococcus (closed black arrow) $(\times 100$, H\&E staining). Inset: High-power view of the open black arrow shows Cryptococcus $(\times 400)$.

Ruxolitinib is a selective inhibitor of JAK1 and JAK2. It was approved in 2011 for treating PMF based on the findings from clinical trials that demonstrated not only a prolonged survival but also improved constitutional symptoms and spleen size in patients with PMF $(1-4,34)$. However, some infectious complications associated with ruxolitinib treatment have been reported $(4,11-25)$. Dioverti et al. reported a review of 32 cases identified as opportunistic infections related to ruxolitinib treatment (22). The majority of the cases involved reactivation of tuberculosis (11 cases, $34 \%$ ), and cryptococcosis was the most frequently reported fungal infection (3 cases, 9\%).

We also conducted a review of previously reported cases of disseminated tuberculosis and/or cryptococcosis associated with ruxolitinib treatment that had clinical information available (11-24) (Table). Our search revealed nine cases, including our case, of disseminated tuberculosis that developed during ruxolitinib treatment (11-18). In addition, we found seven cases of cryptococcosis associated with ruxolitinib treatment, including our case (19-24). Notably, our report was the only case of both disseminated tuberculosis and disseminated cryptococcosis that developed during ruxolitinib treatment. The median age at the diagnosis of disseminated tuberculosis and disseminated cryptococcosis was 73 and 70 years old, respectively. Seven out of 9 cases (78\%) of disseminated tuberculosis and 7 out of 7 cases (100\%) of disseminated cryptococcosis cases involved men. The median duration of ruxolitinib treatment before the diagnosis was 6 (interquartile range, 4-18) months (disseminated tuberculosis, 6 [2-14] months; cryptococcosis, 18 [624] months). Ruxolitinib treatment was discontinued in 8 out of 13 cases $(63 \%)$, including our case (information was unavailable in 2 cases), after the diagnosis. Ruxolitinib treatment was gradually discontinued from six days to four months in four out of the remaining five cases. Furthermore, 5 out of 14 patients $(36 \%)$ died due to these opportunistic infections.

Our case suggests that treatment with ruxolitinib can cause disseminated tuberculosis and disseminated cryptococcosis concomitantly. Treatment with ruxolitinib inhibits the JAK-STAT signaling pathway and results in reduced cellular immunity due to decreased STAT-3 and STAT-5 activation (8). Furthermore, ruxolitinib affects both the differentiation and function of dendritic cells, resulting in inappropriate antigen-specific T-cell activation and reduced cytokine production (9). It also influences the T-cell function by reducing their number and impairing proinflammatory cytokine production (10). These effects of ruxolitinib might lead to a high risk of opportunistic infections, such as disseminated tuberculosis and disseminated cryptococcosis. Tuberculosis also causes changes in cellular immunity and is known to be a predisposing factor for developing cryptococcosis $(35,36)$. Cryptococcosis can also be a predisposing factor to reactivation or infection with tuberculosis through the reduced production of tumor necrosis factor- $\alpha(37,38)$. Consequently, these effects might have resulted in the disseminated tuberculosis and concurrent disseminated cryptococcosis in our case.

In the present patient, although we strongly suspected disseminated tuberculosis as a differential diagnosis, we were unable to initiate anti-tuberculosis treatment due to the disease activity of PMF. It might be acceptable to start preemptive anti-tuberculosis therapy prior to a microbiologically or histologically definitive diagnosis of disseminated tuberculosis after obtaining specimens for mycobacterial culture from the suspected infected organs or tissues. Furthermore, disseminated cryptococcosis was not diagnosed or suspected before the death of the patient, since disseminated tuberculosis was highly suspected as the differential diagnosis. In retrospect, this can be considered an anchoring bias, i.e. a cognitive bias associated with diagnostic inaccuracies or suboptimal management (39). Cryptococcosis, including pulmonary or disseminated cryptococcosis, should be considered in the differential diagnosis of solitary or multiple pulmonary nodules in the subpleural areas of the lung (40-44). Although cavitary lesions tend to be more commonly observed in immunocompromised patients, the findings vary among patients, and consolidation, ground-glass opacity, and reticular opacity, as well as pulmonary nodules, can be observed in patients with pulmonary cryptococcosis (40-44). There- 
Table. Literature Review of Disseminated Tuberculosis And/or Cryptococcosis with Ruxolitinib Treatment in Patients with Myeloproliferative Disorders.

\begin{tabular}{|c|c|c|c|c|c|c|c|c|c|}
\hline Case & Author, year & $\begin{array}{l}\text { Age/ } \\
\text { Sex }\end{array}$ & Region & $\begin{array}{l}\text { Underlying } \\
\text { MPD }\end{array}$ & Diagnosis & Culture & $\begin{array}{c}\text { Time from } \\
\text { initiation of } \\
\text { ruxolitinib to } \\
\text { onset of infection }\end{array}$ & $\begin{array}{l}\text { Ruxolitinib } \\
\text { treatment after } \\
\text { diagnosis of } \\
\text { infection }\end{array}$ & Outcome \\
\hline$\# 1$ & $\begin{array}{l}\text { Colomba et al., } \\
2012[11]\end{array}$ & NA/M & Italy & $\mathrm{PMF}$ & $\begin{array}{l}\text { Disseminated } \\
\text { tuberculosis }\end{array}$ & $\begin{array}{l}\text { Inguinal lymph } \\
\text { node, sputum }\end{array}$ & 2 months & Unspecified & Unspecified \\
\hline$\# 2$ & $\begin{array}{l}\text { Hopman et al., } \\
2014 \text { [12] }\end{array}$ & $62 / \mathrm{M}$ & USA & PMF & $\begin{array}{l}\text { Disseminated } \\
\text { tuberculosis }\end{array}$ & $\begin{array}{c}\text { Bronchoalveolar } \\
\text { lavage fluid, } \\
\text { blood }\end{array}$ & 7 weeks & Discontinued & Alive \\
\hline$\# 3$ & $\begin{array}{l}\text { Shamil et al., } \\
2015 \text { [13] }\end{array}$ & $78 / \mathrm{F}$ & $\mathrm{UK}$ & PMF & $\begin{array}{l}\text { Disseminated } \\
\text { tuberculosis }\end{array}$ & $\begin{array}{l}\text { Cervical lymph } \\
\text { node }\end{array}$ & Unspecified & Discontinued & Alive \\
\hline \#4 & $\begin{array}{l}\text { Branco et al., } \\
2016 \text { [14] }\end{array}$ & $78 / \mathrm{F}$ & France & PMF & $\begin{array}{l}\text { Disseminated } \\
\text { tuberculosis }\end{array}$ & $\begin{array}{l}\text { Cervical lymph } \\
\text { node }\end{array}$ & 27 months & Continued & Alive \\
\hline$\# 5$ & $\begin{array}{l}\text { Abidi et al., } \\
2016[15]\end{array}$ & 69/M & India & PMF & $\begin{array}{l}\text { Disseminated } \\
\text { tuberculosis }\end{array}$ & $\begin{array}{c}\text { Cervical lymph } \\
\text { node }\end{array}$ & 3 weeks & Discontinued & Alive \\
\hline \#7 & $\begin{array}{l}\text { Lescuyer et al., } \\
2019 \text { [17] }\end{array}$ & $73 / \mathrm{M}$ & France & PMF & $\begin{array}{l}\text { Disseminated } \\
\text { tuberculosis }\end{array}$ & Cerebral biopsy & 6 months & Discontinued & Dead \\
\hline$\# 8$ & $\begin{array}{c}\text { Hirai et al., } 2020 \\
{[18]}\end{array}$ & $80 / \mathrm{M}$ & Japan & PMF & $\begin{array}{l}\text { Disseminated } \\
\text { tuberculosis }\end{array}$ & $\begin{array}{l}\text { Sputum, skin } \\
\text { abscess }\end{array}$ & 10 months & $\begin{array}{c}4 \text { months } \\
\text { continued, } \\
\text { discontinued }\end{array}$ & Dead \\
\hline \#9 & $\begin{array}{c}\text { Wysham et al., } \\
2013 \text { [19] }\end{array}$ & $66 / \mathrm{M}$ & USA & $\begin{array}{l}\text { PV and } \\
\text { PMF }\end{array}$ & $\begin{array}{l}\text { Pulmonary } \\
\text { cryptococcosis }\end{array}$ & $\begin{array}{l}\text { Bronchoalveolar } \\
\text { lavage fluid }\end{array}$ & 18 months & $\begin{array}{c}3 \text { weeks } \\
\text { continued, } \\
\text { discontinued, } \\
\text { and restarted }\end{array}$ & Alive \\
\hline$\# 10$ & $\begin{array}{l}\text { Chen et al., } \\
2016 \text { [20] }\end{array}$ & $69 / \mathrm{M}$ & Taiwan & PMF & $\begin{array}{c}\text { Cryptococcal } \\
\text { meningoencephalitis }\end{array}$ & $\begin{array}{l}\text { Cerebrospinal } \\
\text { fluid }\end{array}$ & 46 months & Unspecified & Alive \\
\hline \#11 & $\begin{array}{l}\text { Hirano et al., } \\
2017 \text { [21] }\end{array}$ & $79 / \mathrm{M}$ & Japan & PMF & $\begin{array}{l}\text { Pulmonary } \\
\text { cryptococcosis }\end{array}$ & Lung & 6 months & $\begin{array}{c}5 \text { weeks } \\
\text { continued, } \\
\text { discontinued }\end{array}$ & Alive \\
\hline$\# 13$ & $\begin{array}{l}\text { Prakash et al., } \\
2019 \text { [23] }\end{array}$ & $51 / \mathrm{M}$ & $\begin{array}{l}\text { United } \\
\text { States }\end{array}$ & PV & $\begin{array}{l}\text { Cryptococcal } \\
\text { meningitis and } \\
\text { disseminated } \\
\text { histoplasmosis }\end{array}$ & $\begin{array}{l}\text { Cerebrospinal } \\
\text { fluid }\end{array}$ & 18 months & Discontinued & Alive \\
\hline$\# 14$ & $\begin{array}{l}\text { Tsukui et al., } \\
2020 \text { [24] }\end{array}$ & $76 / \mathrm{M}$ & Japan & PMF & $\begin{array}{l}\text { Cryptococcal } \\
\text { meningitis }\end{array}$ & $\begin{array}{l}\text { Cerebrospinal } \\
\text { fluid }\end{array}$ & 5 months & $\begin{array}{c}6 \text { days } \\
\text { continued, } \\
\text { Discontinued }\end{array}$ & Alive \\
\hline$\# 15$ & $\begin{array}{l}\text { Ogai et al., } 2021 \\
\text { (current case) }\end{array}$ & $71 / \mathrm{M}$ & Japan & PMF & $\begin{array}{l}\text { Disseminated } \\
\text { tuberculosis and } \\
\text { disseminated } \\
\text { cryptococcosis }\end{array}$ & $\begin{array}{c}\text { Sputum, blood, } \\
\text { urine, and } \\
\text { autopsy }^{*}\end{array}$ & 30 months & Discontinued & Dead \\
\hline
\end{tabular}

F: Female, M: Male, MPD: myeloproliferative disorders, NA: not available, PMF: primary myelofibrosis, PV: polycythemia vera

*, Tuberculosis was observed in the lung, liver, spleen, and lymph nodes (mediastinal and retroperitoneal lymph nodes). Cryptococcosis was observed in the lung, liver, spleen, lymph nodes (mediastinal and retroperitoneal lymph nodes), heart, adrenals, and thyroid.

fore, it is often difficult to clinically distinguish between disseminated tuberculosis and cryptococcosis. A serum cryptococcal antigen test should be considered in addition to symptoms and radiological findings for the clinical diagnosis of cryptococcosis in such settings. As a result, we believe it is important for clinicians to recognize not only disseminated tuberculosis but also cryptococcosis as a differential diagnosis when new abnormal shadows appear in lung fields in patients who are treated with ruxolitinib.

The further accumulation of cases is needed to clarify the clinical features of disseminated tuberculosis and cryptococcosis related to treatment with ruxolitinib.
The authors state that they have no Conflict of Interest (COI).

Funding: This research did not receive any specific grant from funding agencies in the public, commercial, or not-forprofit sectors.

Authorship Statement: All authors meet the ICMJE authorship criteria.

Ethics considerations: We obtained consent from the patient's family for the publication of his medical data. Patient privacy was fully protected, and personal information was handled such 
that the patient could not be identified. The study protocol adhered to the tenets of the Declaration of Helsinki.

\section{References}

1. Cervantes F, Vannucchi AM, Kiladjian JJ, Al-Ali HK, Sirulnik A, Stalbovskaya V, et al. Three-year efficacy, safety, and survival findings from COMFORT-II, a phase 3 study comparing ruxolitinib with best available therapy for myelofibrosis. Blood 122: 4047-4053, 2013

2. Harrison C, Kiladjian JJ, Al-Ali HK, Gisslinger H, Waltzman R, Stalbovskaya V, et al. JAK inhibition with ruxolitinib versus best available therapy for myelofibrosis. N Engl J Med 366: 787-798, 2012.

3. Deisseroth A, Kaminskas E, Grillo J, Chen W, Saber H, Lu HL, et al. U.S. Food and Drug Administration approval: ruxolitinib for the treatment of patients with intermediate and high-risk myelofibrosis. Clin Cancer Res 18: 3212-3217, 2012.

4. Verstovsek S, Mesa RA, Gotlib J, Levy RS, Gupta V, DiPersio JF, et al. A double-blind, placebo-controlled trial of ruxolitinib for myelofibrosis. N Engl J Med 366: 799-807, 2012.

5. Baxter EJ, Scott LM, Campbell PJ, East C, Fourouclas N, Swanton S, et al. Acquired mutation of the tyrosine kinase JAK2 in human myeloproliferative disorders. Lancet 365: 1054-1061, 2005.

6. Elli EM, Barate C, Mendicino F, Palandri F, Palumbo GA. Mechanisms Underlying the Anti-inflammatory and Immunosuppressive Activity of Ruxolitinib. Front Oncol 9: 1186, 2019.

7. Harrison CN, Vannucchi AM, Kiladjian JJ, Al-Ali HK, Gisslinger $\mathrm{H}$, Knoops L, et al. Long-term findings from COMFORT-II, a phase 3 study of ruxolitinib vs best available therapy for myelofibrosis. Leukemia 30: 1701-1707, 2016.

8. McLornan DP, Khan AA, Harrison CN. Immunological Consequences of JAK Inhibition: Friend or Foe? Curr Hematol Malig Rep 10: 370-379, 2015.

9. Heine A, Held SA, Daecke SN, Wallner S, Yajnanarayana SP, Kurts $\mathrm{C}$, et al. The JAK-inhibitor ruxolitinib impairs dendritic cell function in vitro and in vivo. Blood 122: 1192-1202, 2013.

10. Parampalli Yajnanarayana S, Stubig $T$, Cornez $I$, Alchalby $H$, Schonberg K, Rudolph J, et al. JAK1/2 inhibition impairs T cell function in vitro and in patients with myeloproliferative neoplasms. Br J Haematol 169: 824-833, 2015.

11. Colomba C, Rubino R, Siracusa L, Lalicata F, Trizzino M, Titone $\mathrm{L}$, et al. Disseminated tuberculosis in a patient treated with a JAK 2 selective inhibitor: a case report. BMC Research Notes 5: 2012.

12. Hopman RK, Lawrence SJ, Oh ST. Disseminated tuberculosis associated with ruxolitinib. Leukemia 28: 1750-1751, 2014.

13. Shamil E, Cunningham D, Wong BL, Jani P. Ruxolitinib Associated Tuberculosis Presenting as a Neck Lump. Case Rep Infect Dis 2015: 284168, 2015.

14. Branco B, Metsu D, Dutertre M, Marchou B, Delobel P, Recher $\mathrm{C}$, et al. Use of rifampin for treatment of disseminated tuberculosis in a patient with primary myelofibrosis on ruxolitinib. Ann Hematol 95: 1207-1209, 2016.

15. Abidi MZ, Haque J, Varma P, Olteanu H, Guru Murthy GS, Dhakal B, et al. Reactivation of Pulmonary Tuberculosis following Treatment of Myelofibrosis with Ruxolitinib. Case Rep Hematol 2016: 2389038, 2016.

16. Tsukamoto Y, Kiyasu J, Tsuda M, Ikeda M, Shiratsuchi M, Ogawa Y, et al. Fatal Disseminated Tuberculosis during Treatment with Ruxolitinib Plus Prednisolone in a Patient with Primary Myelofibrosis: A Case Report and Review of the Literature. Intern Med 57: 1297-1300, 2018

17. Lescuyer S, Ledoux MP, Gravier S, Natarajan-Ame S, Duval C, Maloisel F, et al. Tuberculosis and atypical mycobacterial infec- tions in ruxolitinib-treated patients with primary or secondary myelofibrosis or polycythemia vera. Int J Infect Dis 80: 134-136, 2019.

18. Hirai N, Kasahara K, Yoshihara S, Nishimura T, Omori K, Ogawa $\mathrm{Y}$, et al. Necessity to screen and treat latent tuberculosis before ruxolitinib treatment-Ruxolitinib-associated disseminated tuberculosis: A case report and literature review. IDCases 21: e00892, 2020.

19. Wysham NG, Sullivan DR, Allada G. An opportunistic infection associated with ruxolitinib, a novel janus kinase 1,2 inhibitor. Chest 143: 1478-1479, 2013.

20. Chen CC, Chen YY, Huang CE. Cryptococcal meningoencephalitis associated with the long-term use of ruxolitinib. Ann Hematol 95: 361-362, 2016.

21. Hirano A, Yamasaki M, Saito N, Iwato K, Daido W, Funaishi K, et al. Pulmonary cryptococcosis in a ruxolitinib-treated patient with primary myelofibrosis. Respir Med Case Rep 22: 87-90, 2017.

22. Dioverti MV, Abu Saleh OM, Tande AJ. Infectious complications in patients on treatment with Ruxolitinib: case report and review of the literature. Infect Dis (Lond) 50: 381-387, 2018.

23. Prakash K, Richman D. A case report of disseminated histoplasmosis and concurrent cryptococcal meningitis in a patient treated with ruxolitinib. BMC Infect Dis 19: 287, 2019.

24. Tsukui D, Fujita H, Suzuki K, Hirata K. A case report of cryptococcal meningitis associated with ruxolitinib. Medicine (Baltimore) 99: e19587, 2020.

25. Harrison CN, Vannucchi AM, Kiladjian JJ, Al-Ali HK, Gisslinger $\mathrm{H}$, Knoops L, et al. Long-term findings from COMFORT-II, a phase 3 study of ruxolitinib vs best available therapy for myelofibrosis. Leukemia 31: 775, 2017.

26. Godbole G, Gant V. Respiratory tract infections in the immunocompromised. Curr Opin Pulm Med 19: 244-250, 2013.

27. Kuroda A, Tasaka S, Yagi K, Mochimaru T, Tani T, Namkoong H, et al. A Case of Disseminated Cryptococcal Infection and Concurrent Lung Tuberculosis in a Patient under Steroid Therapy for Interstitial Pneumonia. Case Rep Pulmonol 2015: 358926, 2015.

28. Kahn FW, England DM, Jones JM. Solitary pulmonary nodule due to Cryptococcus neoformans and Mycobacterium tuberculosis. Am J Med 78: 677-681, 1985.

29. Van Tongeren L, Shaipanich T, Fleetham JA. Coinfection with Cryptococcus gattii and Mycobacterium tuberculosis in an otherwise healthy 18-year-old woman. Can Respir J 18: e62-e63, 2011.

30. Thomas R, Christopher DJ, Balamugesh T, James P, Thomas M. Endobronchial pulmonary cryptococcosis and tuberculosis in an immunocompetent host. Singapore Med J 53: e32-e34, 2012.

31. Kakeya H, Izumikawa $K$, Yamada $K$, Obata $Y$, Nishino $T$, Takazono T, et al. Three cases of concurrent infection with Mycobacterium tuberculosis and Cryptococcus neoformans. Intern Med 53: 1685-1692, 2014.

32. Passamonti F, Cervantes F, Vannucchi AM, Morra E, Rumi E, Pereira A, et al. A dynamic prognostic model to predict survival in primary myelofibrosis: a study by the IWG-MRT (International Working Group for Myeloproliferative Neoplasms Research and Treatment). Blood 115: 1703-1708, 2010.

33. Gangat N, Caramazza D, Vaidya R, George G, Begna K, Schwager S, et al. DIPSS plus: a refined Dynamic International Prognostic Scoring System for primary myelofibrosis that incorporates prognostic information from karyotype, platelet count, and transfusion status. J Clin Oncol 29: 392-397, 2011.

34. Ostojic A, Vrhovac R, Verstovsek S. Ruxolitinib for the treatment of myelofibrosis: its clinical potential. Ther Clin Risk Manag 8: 95-103, 2012.

35. Nagrajan S, Gugnani HC, Kowshik T. Case report. Meningitis due to Cryptococcus neoformans var. neoformans serotype AD associated with pulmonary tuberculosis. Mycoses 43: 67-69, 2000. 
36. Bottasso O, Bay ML, Besedovsky H, del Rey A. Immunoendocrine alterations during human tuberculosis as an integrated view of disease pathology. Neuroimmunomodulation 16: 68-77, 2009.

37. Flynn JL, Goldstein MM, Chan J, Triebold KJ, Pfeffer K, Lowenstein CJ, et al. Tumor necrosis factor-alpha is required in the protective immune response against Mycobacterium tuberculosis in mice. Immunity 2: 561-572, 1995.

38. Huffnagle GB, Chen GH, Curtis JL, McDonald RA, Strieter RM, Toews GB. Down-regulation of the afferent phase of $\mathrm{T}$ cellmediated pulmonary inflammation and immunity by a high melanin-producing strain of Cryptococcus neoformans. J Immunol 155: 3507-3516, 1995.

39. Saposnik G, Redelmeier D, Ruff CC, Tobler PN. Cognitive biases associated with medical decisions: a systematic review. BMC Med Inform Decis Mak 16: 138, 2016.

40. Xie LX, Chen YS, Liu SY, Shi YX. Pulmonary cryptococcosis: comparison of CT findings in immunocompetent and immunocompromised patients. Acta Radiol 56: 447-453, 2015.

41. Zavala S, Baddley JW. Cryptococcosis. Semin Respir Crit Care
Med 41: 69-79, 2020.

42. Perfect JR, Dismukes WE, Dromer F, Goldman DL, Graybill JR, Hamill RJ, et al. Clinical practice guidelines for the management of cryptococcal disease: 2010 update by the infectious diseases society of america. Clin Infect Dis 50: 291-322, 2010.

43. Khoury MB, Godwin JD, Ravin CE, Gallis HA, Halvorsen RA, Putman CE. Thoracic cryptococcosis: immunologic competence and radiologic appearance. AJR Am J Roentgenol 142: 893-896, 1984.

44. Kishi K, Homma S, Kurosaki A, Kohno T, Motoi N, Yoshimura $\mathrm{K}$. Clinical features and high-resolution CT findings of pulmonary cryptococcosis in non-AIDS patients. Respir Med 100: 807-812, 2006.

The Internal Medicine is an Open Access journal distributed under the Creative Commons Attribution-NonCommercial-NoDerivatives 4.0 International License. To view the details of this license, please visit (https://creativecommons.org/licenses/ by-nc-nd/4.0/).

(C) The Japanese Society of Internal Medicine Intern Med Advance Publication 